GONTIJO, B.B. et al. Esporotricose e Leishmaniose Tegumentar em cães e gatos: semelhanças e diferenças. PUBVET, Londrina, V. 5, N. 38, Ed. 185, Art. 1250, 2011.

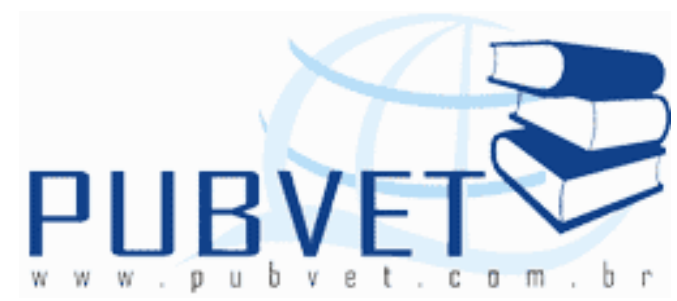

PUBVET, Publicações em Medicina Veterinária e Zootecnia.

\title{
Esporotricose e Leishmaniose Tegumentar em cães e gatos: semelhanças e diferenças
}

Bernardo B. Gontijo ${ }^{1}$, Felipe F. Pavão ${ }^{1}$, Fernando S. A. Silva ${ }^{1}$, Frederico D. Silva ${ }^{1}$, Guilherme C. Tavares ${ }^{2}$, Guilherme L. Coelho ${ }^{1}$

${ }^{1}$ Acadêmico do Curso de Medicina Veterinária da PUC- Minas Betim.

2 Médico Veterinário, coodernador do GEAQUA PUC- Minas Betim.

Email: gui.ichijoji@hotmail.com

\section{Resumo}

A Esporotricose e a Leishmaniose Tegumentar são duas dermatoses que acometem cães e gatos, além de possuírem alto potencial zoonótico. Por apresentarem lesões semelhantes nos animais acometidos, se torna essencial a caracterização epidemiológica, sintomatológica, métodos efetivos de diagnóstico e controle, a fim de se escolher a abordagem terapêutica mais conveniente ao caso e como conseqüência proteção dos seres humanos quanto às estas enfermidades. Palavras-chave: pele, zoonose, cães, gatos. 
GONTIJO, B.B. et al. Esporotricose e Leishmaniose Tegumentar em cães e gatos: semelhanças e diferenças. PUBVET, Londrina, V. 5, N. 38, Ed. 185, Art. 1250, 2011.

\title{
Sporotrichosis and Cutaneous Leishmaniasis in dogs and cats: similarities and differences
}

\begin{abstract}
The Sporotrichosis and leishmaniasis are two skin conditions that affect dogs and cats, and they have a high zoonotic potential. As they have similar lesions in affected animals, it is essential to characterize the epidemiological, symptomatology, diagnosis and effective methods of control, in order to choose the most appropriate therapeutic approach to the case and consequently the protection of human beings regarding these diseases.
\end{abstract}

Keywords: skin, zoonosis, dogs, cats.

\section{INTRODUÇÃO}

A esporotricose é a doença causada pelo fungo Sporothrix schenckii, de caráter zoonótico ${ }^{7,25}$, que possui a capacidade de infectar várias espécies de animais, inclusive o ser humano $12,13,17,19,23,26,27$, possui distribuição mundial, sendo especialmente observado nas regiões de climas tropicais e temperados ${ }^{11}$, e encontrados em solos ricos em material decomposto, em vegetações deterioradas, atuando como microorganismo saprófita ${ }^{11,12,17,18,19,20,25,26}$. A transmissão pode ocorrer através da penetração do microorganismo em feridas ou contato direto animal-planta ou animal-solo contaminado.

Já a Leishmaniose Tegumentar (LT) é doença causada pelo protozoário do gênero Leishmania, que afeta pele e mucosas de humanos e animais ${ }^{5,6,7,21,24}$. Apresenta distribuição mundial, sendo descritas ocorrências em 88 países, com registro anual de cerca de 1,5 milhões de casos em humanos ${ }^{6}$. Para que ocorra a transmissão do parasito entre animais domésticos, silvestres e humanos é necessário a presença de vetor, flebotomíneo, e o repasto em hospedeiros vertebrados ${ }^{7}$. 
GONTIJO, B.B. et al. Esporotricose e Leishmaniose Tegumentar em cães e gatos: semelhanças e diferenças. PUBVET, Londrina, V. 5, N. 38, Ed. 185, Art. 1250, 2011.

O presente trabalho tem como objetivo comparar a esporotricose e a LT que afetam cães e gatos, relacionando semelhanças e diferenças quanto a morfologia do agente, formas de transmissão, sinais clínicos envolvidos, métodos de diagnóstico, tratamento, prevenção e controle destas duas dermatoses zoonóticas.

\section{REVISÃO DE LITERATURA}

\section{1 - Esporotricose em cães e gatos}

A esporotricose é a doença causada pelo fungo Sporothrix schenckii, de caráter zoonótico 7,25 , que possui a capacidade de infectar várias espécies de animais, inclusive o ser humano $12,13,17,19,23,26,27$. Dentre os animais domésticos, é relatada maior incidência em gatos ${ }^{20}$, enquanto que em cães, é considerada rara ${ }^{15}$. Morfologicamente, o S. Schenckii, fungo aeróbio dimórfico, ou seja, apresenta-se tanto na forma filamentosa, observado em temperatura ambiente, quanto a leveduriforme, à $37^{\circ} \mathrm{C}$, in vitro ou em tecidos de organismo vivo ${ }^{19,27}$. Nesta forma, apresenta-se no formato característico de charuto ou cigarrete, mensurando cerca de 2 por $3 \mu \mathrm{m}$ a 3 por $10 \mu \mathrm{m}^{26}$. Este microorganismo apresenta reprodução sexuada na forma leveduriforme ${ }^{19}$.

O S. schenckii tem distribuição mundial, sendo especialmente observado nas regiões de climas tropicais e temperados ${ }^{11}$, sendo encontrado em solos ricos em material decomposto, em vegetações deterioradas, atuando como microorganismo saprófita ${ }^{11,12,17,18,19,20,25,26}$. A transmissão pode ocorrer através da penetração do microorganismo em feridas ou contato direto animal-planta ou animal-solo contaminado. Nos cães, a infecção está associada a feridas perfurantes por espinhos ou lascas de madeiras, enquanto que felinos, a infecção ocorre principalmente por brigas entre os animais, onde o animal sadio é infectado pelo microorganismo presente nas garras do animal doente ${ }^{9,19}$. A 
GONTIJO, B.B. et al. Esporotricose e Leishmaniose Tegumentar em cães e gatos: semelhanças e diferenças. PUBVET, Londrina, V. 5, N. 38, Ed. 185, Art. 1250, 2011.

transmissão por inalação do microorganismo presente no solo e em vegetações em decomposição é considerada rara ${ }^{17}$. Por se tratar de zoonose, a transmissão para humanos é oriunda principalmente do contato gato-homem, sendo que a contaminação é decorrente de ferida perfurante (inoculação direta: arranhadura, mordedura) de gato infectado ${ }^{15,19,20,26}$, mas também, é descrito na literatura, a transmissão por contato direto com as lesões cutâneas dos felinos, onde se observa grande quantidade de células leveduriformes, tendo maior prevalência de casos em médicos veterinários, enfermeiros e nos proprietários dos animais $^{13,18}$.

A esporotricose apresenta-se como micose cutânea granulomatosa a piogranulomatosa com evolução subaguda ou crônica ${ }^{11}$. Sendo descritas três formas clínicas: a cutânea, a linfocutânea e a disseminada9,17. Em um mesmo animal pode ser observado mais de um tipo de forma clínica. Geralmente, as lesões são observadas na região dorsal da cabeça e do tronco , mas os membros e cauda também podem ser acometidos ${ }^{17}$. Nos cães, é relatada a forma cutânea, caracterizada por presença de nódulos (uni ou multinodular) e firmes, placas ulceradas e não pruriginosas, com bordas elevadas, crostas e áreas alopecicas $^{11,26}$, principalmente no tronco, cabeça e orelhas ${ }^{26}$. Os nódulos podem ulcerar ou drenar secreções. A forma linfocutânea é caracterizada pela infecção ascendente pela via linfática de um nódulo infectado, e, a forma disseminada é rara $^{26}$. Nos gatos, a forma cutânea também é a mais freqüente, caracterizada por lesões papulonodulares, localizadas geralmente na cabeça, na parte distal dos membros e/ou base da cauda ${ }^{9,17}$. Inicialmente, as lesões assemelham-se a feridas decorrentes de brigas, formações de abcessos, celulite e fístulas não responsivas ao tratamento com antibióticos ${ }^{9}$. Posteriormente, ocorre 0 desenvolvimento de pequenos nódulos com tamanhos variando de um a três centímetros de diâmetro no local da inoculação, atingindo vasos linfáticos e formando novos nódulos ${ }^{19}$. As áreas afetadas podem se ulcerar e drenar exsudato 
GONTIJO, B.B. et al. Esporotricose e Leishmaniose Tegumentar em cães e gatos: semelhanças e diferenças. PUBVET, Londrina, V. 5, N. 38, Ed. 185, Art. 1250, 2011.

sero-hemorrágico $^{19}$ a purulento, promovendo a formação de crostas espessadas $^{17}$. O quadro pode evoluir para extensas áreas de necrose com possível exposição de músculos e ossos ${ }^{17}$. A disseminação da enfermidade ocorre devido aos hábitos de higiene da espécie felina (auto-inoculação), tendo em média três meses de período de incubação ${ }^{19}$. Esta forma clínica, está associada a distúrbios sistêmicos com a progressão da infecção através de difusão hematogênica ou tecidual ${ }^{19}$, acometendo pulmões, fígado, trato gastrointestinal, sistema nervoso central, baço, rins, testículos, mama, articulações ou ossos ${ }^{9,19}$. A forma disseminada é rara, porém fatal, quando não observadas às formas cutâneas e linfocutâneas, ou mesmo, quando o animal apresentar quadro de imunossupressão ${ }^{19}$. Embora a enfermidade sistêmica encontre-se ausente, a doença crônica pode resultar em quadro de letargia, prostração, anorexia, depressão e hipertermia ${ }^{9,17}$.

O diagnóstico baseia-se na anamnese bem apurada, buscando do proprietário o histórico mais concreto, além do exame físico e dermatológico realizado pelo médico veterinário, auxiliado por exames laboratoriais ${ }^{17,19}$. Um ponto importante no histórico é a antibioticoterapia utilizada anteriormente sem sucesso no controle das lesões ${ }^{19}$. Dentre os métodos de exames complementares podem ser citados: exame citopatológico ${ }^{17,19,26}$, microscopia direta ${ }^{19}$, cultura fúngica ${ }^{11,16,17,19,20,26}$, imunohistoquímica ${ }^{16}, \mathrm{PCR}^{20}$, e alterações post morten na necropsia ${ }^{19,23}$. Dentre os citados, a cultura fúngica é o de escolha ${ }^{19}$.

O exame citopatológico consiste na visualização de estruturas leveduriformes coradas pela prata ou pelo àcido Periódo de Schiff, em macrófagos ou no meio extracelular, porém deve-se tomar cuidado ao coletar amostras citológicas das lesões devido ao potencial zoonótico da enfermidade ${ }^{14,19}$.

O exame microscópico direto em esfregaços de pus ou secreções do local da lesão, corado pelo método de Giemsa, revela presença de células leveduriformes pequenas, esféricas, ovóides ou na forma de charuto em casos positivos ${ }^{19}$. 
GONTIJO, B.B. et al. Esporotricose e Leishmaniose Tegumentar em cães e gatos: semelhanças e diferenças. PUBVET, Londrina, V. 5, N. 38, Ed. 185, Art. 1250, 2011.

A cultura fúngica é o método definitivo para o diagnóstico da enfermidade, para tanto, coleta-se pus e secreção da ferida, semeando-o em Agar Sabourand Glicose com Cloranfenicol e Ciclo-hexadina, para evitar contaminação ambiental. Incuba-se a $25^{\circ} \mathrm{C}$ de três a cinco dias e depois avalia-se macro e microscopicamente a presença do fungo ${ }^{17,19}$. Cita-se na literatura a necessidade da conversão da forma filamentosa para a leveduriforme, através da incubação da amostra em $37^{\circ} \mathrm{C}^{11,19,20}$.

Outros exames complementares são relatados em literatura estrangeira, como por exemplo, a imunohistoquímica ${ }^{16}$ e $0 \mathrm{PCR}^{20}$. Ambos apresentam bons resultados, mas não são de rotina clínica. Experimentalmente, em nosso país, a alternativa de diagnóstico seria a utilização de cultura de coágulo sanguíneo, que se demonstrou eficiente e econômico, além de poder utilizar o soro da amostra para outras provas laboratoriais ${ }^{23}$.

O diagnóstico da forma disseminada da doença normalmente só é realizado com a necropsia do animal ${ }^{19,23}$.

Como diagnóstico diferencial pode-se citar: o complexo granuloma eosinofífico, abscesso, LT, demodicose, escabiose, actinomicose, nocardiose, tuberculose, histoplasmose, criptococose, corpo estranho e neoplasias ${ }^{11,17}$.

O tratamento da esporotricose, forma cutânea e linfocutânea, consiste na utilização medicamentosa de iodetos inorgânicos, associados ou não a antifúgicos, como o Cetaconazol e Itraconazol ${ }^{11,17,19,26}$. Os gatos, apesar de terem sensibilidade ao Iodeto de Potássio, podem ser tratados com o mesmo $\left(20 \mathrm{mg} / \mathrm{kg}^{17}\right.$ a $44 \mathrm{mg} / \mathrm{kg}^{26}$, com intervalo médio de 12 horas entre cada aplicação,durante 2 meses ou mais), porém a medicação preconizada é o Itraconazol $\left(10 \mathrm{mg} / \mathrm{kg}\right.$ a cada $12-24$ horas $^{17}$ durante 2 meses ou mais). Os cães são responsíveis ao tratamento com Iodeto de Potássio $(40 \mathrm{mg} / \mathrm{kg}$ a cada 8-12 horas durante 2 meses ou mais), ao itraconazol e ao cetaconazol $(10 \mathrm{mg} / \mathrm{kg} \mathrm{a}$ cada $12-24$ horas durante dois meses ou mais) ${ }^{11,17}$. O tratamento deve ser 
GONTIJO, B.B. et al. Esporotricose e Leishmaniose Tegumentar em cães e gatos: semelhanças e diferenças. PUBVET, Londrina, V. 5, N. 38, Ed. 185, Art. 1250, 2011.

estendido por 30 dias após a cura clínica, e a eficácia do tratamento só é afirmada após cicatrização das feridas e culturas fúngicas negativas ${ }^{17,26}$. Devido ao uso indiscriminado do Itraconazol no tratamento da esporotricose, já se tem relatos de resistência ao fármaco em cães e gatos, ocasionando falhas terapêuticas. Para estes casos, experimentalmente está sendo utilizada in vitro, a Terbinafina $\left(16 \mu \mathrm{g} / \mathrm{ml}\right.$ a $\left.0,03 \mu \mathrm{g} / \mathrm{ml}^{13}\right)$, antifúngico do grupo das alilaminas, que até o momento está apresentando resultados eficazes ${ }^{13}$.

Por se tratar de doença com alto potencial zoonótico, medidas preventivas devem ser tomadas como: tratamento e isolamento de animais doentes até a cura clínica, desinfecção das instalações com hipoclorito de sódio onde estes animais vivem, visando a não disseminação da doença; animais suspeitos que vierem a óbito é recomendada a cremação ${ }^{3}$, evitando assim, a permanência do fungo no ambiente; castrar machos, o que reduziria os índices de brigas de animais que vão as ruas, e que gerariam feridas e acidentalmente seriam porta de entrada para 0 patógeno ${ }^{17}$; advertir aos proprietários quanto ao risco de transmissibilidade da doença aos humanos para um manejo domiciliar mais cauteloso e evitar contaminação, indicando assim, higienização adequada após qualquer contato $^{19}$; educação quanto a posse responsável de animais domésticos ${ }^{3}$; em clínicas veterinárias, o uso de luvas deve ser obrigatório, e gatos suspeitos devem ser contidos para evitar arranhaduras e mordeduras. Após o exame clinico do animal, fazer higienização adequada das mãos, descartar o material utilizado e esterilizar o local do procedimento ${ }^{19}$.

Uma curiosidade quanto a esporotricose em humanos, é o relato da regressão espontânea das lesões em gestantes mediada pelo sistema imune humoral, porém isso é muito pouco estudado e nos cães e gatos, não há nenhuma correlação ainda descrita ${ }^{1}$. 
GONTIJO, B.B. et al. Esporotricose e Leishmaniose Tegumentar em cães e gatos: semelhanças e diferenças. PUBVET, Londrina, V. 5, N. 38, Ed. 185, Art. 1250, 2011.

\section{2 - Leishmaniose Tegumentar em cães e gatos}

A LT é doença causada pelo protozoário do gênero Leishmania, que afeta pele e mucosas de humanos e animais ${ }^{5,6,7,21,24}$. Estes protozoários pertencem à ordem Kinetoplastida, da família Trypanosomatidae ${ }^{7}$, apresentando-se como parasito intracelular obrigatório de células do sistema fagocítico mononuclear, sendo descritas duas formas: promastigota ou flagelada, encontrado no tudo digestivo do inseto vetor, e a forma amastigota, observadas nos tecidos dos animais vertebrados ${ }^{6}$. Estes protozoários são responsáveis pela ocorrência tanto da LV quanto à LT. O que diferencia o surgimento de cada enfermidade é a espécie envolvida, sendo que a primeira ocorre pela infecção do protozoário Leishmania infantum, também conhecida como L. chagasi, enquanto que a forma tegumentar ocorre pela infecção com as espécies de (Leishmania) amazonensis, (Viannia) guyanensis, L. (V.) lainsoni, L. (V.) naiffi, L. (V.) shawi e L. (V.) braziliensis'. Morfologicamente, estes microorganismos são redondos a ovais, com 2 a $4 \mu \mathrm{m}$ de tamanho, contendo núcleo esférico e basofílico, e pequeno cinetoplasto em forma de bastonete, quando observados em sua forma amastigota?.

A literatura ainda é carente de estudos relacionados quanto aos aspectos clínicos, parasitológicos e imunológicos referente à $L_{T}$ em cães e em gatos ${ }^{7}$, porém já se tem relatos de gatos infectados com (Leishmania) amazonensis no Brasil ${ }^{24}$, e cães infectados na América Latina ${ }^{10,14,21}$.

A LT apresenta distribuição mundial, sendo descritas ocorrências em 88 países, com registro anual de cerca de 1,5 milhões de casos em humanos ${ }^{6}$. No Brasil, apresenta-se distribuída em todos os Estados, com notificação de cerca de $37 \mathrm{mil}$ casos humanos entre os anos de 1997 a $2001^{5,7}$. Originalmente pensava-se que se tratava de zoonose de animais silvestres, já que casos humanos só ocorriam quando os mesmos entravam em focos endêmicos, florestas, áreas de desmatamento e extrativismo ${ }^{5,21}$, porém ocorreu alteração do cenário, sendo 
GONTIJO, B.B. et al. Esporotricose e Leishmaniose Tegumentar em cães e gatos: semelhanças e diferenças. PUBVET, Londrina, V. 5, N. 38, Ed. 185, Art. 1250, 2011.

observados casos próximos ao centros urbanos e domiciliares, o que implica na suspeita de animais domésticos como reservatórios dos agentes infecciosos ${ }^{5,7,21}$. Para que ocorra a transmissão do parasito entre animais domésticos, silvestres e humanos é necessário a presença de vetor, flebotomíneo, que é um díptero pertencente à subfamília Phlebotominae. O gênero mais importante no Brasil e no continente americano desta subfamília é o Lutzomyia, sendo os casos humanos normalmente transmitidos pelas espécies Lutzomyia whitmani ou intermedia ${ }^{2,7}$. Os flebotomíneos possuem hábitos crepusculares ou noturnos, dependem de matéria orgânica para o desenvolvimento do seu ciclo evolutivo. Habitavam tipicamente as matas, porém, com a destruição dos seus habitats naturais e a disponibilidade de matéria orgânica no ambiente, são facilmente encontrados na região urbana e domiciliar ${ }^{7}$. É relatado que alguns animais silvestres, gambá, por exemplo, e alguns animais domésticos (cães) agem como reservatórios naturais das leishmanioses ${ }^{7}$. Na LT especificamente, existe a documentação de cães, gatos, eqüídeos e roedores domésticos infectados que participariam na observação da enfermidade na região urbana, porém, o envolvimento destes animais no ciclo de transmissão não foram esclarecidos ${ }^{7}$.

Sucintamente, o ciclo evolutivo da leishmaniose ocorre pelo repasto dos flebotomineos em hospedeiros vertebrados, que irão ingerir as formas amastigotas presentes em macrófagos destes hospedeiros infectados. Nos flebotomíneos, os parasitos se multiplicam e passam para a forma promastigota que serão inoculadas em outro hospedeiro após novo repasto sanguíneo. Após essa inoculação, os parasitos infectam macrófagos da pele e adquirem novamente a forma amastigota?.

Em cães, a LT geralmente apresenta como sintomatologia: lesões ulceradas no pavilhão auricular, no focinho, na bolsa escrotal e na face ${ }^{6,7}$. A doença tem curso crônico, o animal mantêm-se estável sistemicamente, porém as lesões podem aumentar em número e extensão, apresentar cura espontânea com recidivas 
GONTIJO, B.B. et al. Esporotricose e Leishmaniose Tegumentar em cães e gatos: semelhanças e diferenças. PUBVET, Londrina, V. 5, N. 38, Ed. 185, Art. 1250, 2011.

posteriores, como também pode agravar, afetando mucosa nasal ${ }^{7}$. Mas o que prevalece na literatura são achados de lesões únicas nos animais. Nos felinos, apesar de raramente manifestar leishmaniose, a forma tegumentar é a mais comum, sendo observados sintomatologia como: lesões ulceradas ou crostosas no plano nasal, nos lábios, no pavilhão auricular e nas pálpebras ${ }^{7,24}$.

Para o diagnóstico da LT devem ser consideradas as lesões encontradas e relacioná-las com outras doenças que causem úlceras cutâneas, tais como neoplasias, piodermatites, micoses $^{6}$, pênfigo foliáceo, lúpus eritematoso sistêmico, dermatose responsiva ao zinco, eritema necrolítico migratório, adenite sebácea e o linfoma ${ }^{7}$. Entre as micoses, a esporotricose é diferencial importante, pois além de ser tratar de zoonose, apresentam lesões muito semelhantes as da LT, além da ocorrência cada vez mais freqüente nas cidades ${ }^{6}$.

Quanto ao diagnóstico laboratorial, a literatura descreve a utilização do exame direto como diagnóstico mais confiável ${ }^{7,8,24}$, além de mencionar outros exames de mesmo valor diagnóstico com $0 \operatorname{ELISA}^{4,6,7,8}$, O $\operatorname{RIFI}^{4,6,7,8}$, Fixação de Complemento ${ }^{7}, \mathrm{PCR}^{7,21}$, e recentemente a utilização de Citometria de Fluxo para a diferenciação de LV da LT através de IgG's específicos, porém ainda experimentalmente ${ }^{22}$.

Dentre os exames laboratoriais acima citados, rotineiramente são indicados o exame direto através de material proveniente de raspado e biopsia de pele, aspirados de medula óssea e/ou linfonodos ${ }^{7}$. Nestes aspirados das lesões, em animais positivos, podem ser visualizada a forma amastigota do parasito extracelular ou no interior de macrófagos ${ }^{7,24}$, a não visualização das formas amastigotas não descarta a possibilidade do animal ser positivo, só evidencia que aquela área de punção não foi encontrada a presença do parasito. Por isso, exames sorológicos são comumente utilizados em clínicas veterinárias, como o ELISA e o RIFI ${ }^{6,7}$, que possam identificar a presença de anticorpos específicos para a leishmaniose, devido a alta sensibilidade e especificidade da associação 
GONTIJO, B.B. et al. Esporotricose e Leishmaniose Tegumentar em cães e gatos: semelhanças e diferenças. PUBVET, Londrina, V. 5, N. 38, Ed. 185, Art. 1250, 2011.

destes dois métodos, sendo respectivamente $95 \%{ }^{8}$ e $86,2 \%{ }^{4}$. Estes dois exames sorológicos são preconizados pelo MAPA como diagnóstico comprobatório de $L_{V}{ }^{5}$. O PCR é o exame mais eficiente e capaz de identificar a espécie envolvida7,21, apresentando $100 \%$ de especificidade e taxa de diagnósticos positivos quase $60 \%$ maior que os alcançados com sorologia ${ }^{21}$. Muitos laboratórios particulares oferecem essa opção de diagnóstico, mas o custo ainda é alto, o que levam muitos proprietários a realizarem apenas o exame sorológico.

O tratamento das leishmanioses nos animais ainda é bastante discutido, já que não se obtém a cura parasitológica da enfermidade, mas proporciona maior qualidade de vida e maior longevidade aos animais afetados. Ao diagnosticar a enfermidade, o proprietário deve ser informado sobre a mesma, sobre a possibilidade de transmissão desta, sobre as medidas profiláticas que devem ser tomadas, sobre os custos que um tratamento pode acarretar, além de uma avaliação clínica mais criteriosa do paciente, avaliando a condição do mesmo perante o tratamento, através da avaliação de hemograma, proteínas séricas, função renal e hepática. O tratamento da leishmaniose não é preconizado pelo Ministério da Saúde, que recomenda a eutanásia dos animais infectados para o controle da doença ${ }^{7}$. Porém, muitas clínicas veterinárias tratam os animais, resguardadas de ação liminar judicial, com a associação de drogas a base de alopurinol e anfotericina B, para cães com LV. Quanto a LT, como ainda não há confirmação do animal ser fonte de infecção para os humanos ${ }^{22}$, é ainda muito questionável a eutanásia dos mesmos como forma de controle, tanto que o Ministério da Saúde indica a eutanásia dos animais doentes quando as lesões evoluírem para o agravamento das afecções cutâneas, com surgimento de lesões mucosas e infecções secundárias que conduzirão o animal ao sofrimento ${ }^{5}$.

Medidas profiláticas devem ser tomadas para evitar o surgimento de qualquer forma da leishmaniose, e nisso abrange três pontos importantes: controle ambiental e individual ${ }^{7}$, controle de animais doentes/eutanasia ${ }^{7}$ e controle do 
GONTIJO, B.B. et al. Esporotricose e Leishmaniose Tegumentar em cães e gatos: semelhanças e diferenças. PUBVET, Londrina, V. 5, N. 38, Ed. 185, Art. 1250, 2011.

vetor $^{5,10}$. Visando a proteção do animal, recomenda-se a utilização de coleiras impregnadas com deltametrina 4\%, com troca a cada 6 meses; limpeza do ambiente dos canis, retirando o excesso de matéria orgânica; aplicação de inseticidas a base de cipermetrina mensalmente nos canis; plantio de citronela e/ou neem, nos jardins, já que estas possuem ação repelente em insetos; e evitar passeios crepusculares ou noturnos, horário de maior atividade do flebotomíneo ${ }^{7}$. Não existe vacina registrada contra LT.

As medidas ambientais visam o controle do vetor através da limpeza de quintais e terrenos, alterando assim, as condições que proporcionem o estabelecimento de criadouros de formas imaturas do vetor; poda de árvores, visando aumentar a insolação sobre o solo, o que reduziria as condições favoráveis, de temperatura e umidade, para o desenvolvimento de larvas dos flebotomíneos; e destino adequado do lixo orgânico, a fim de impedir a aproximação de reservatórios silvestres, como marsupiais e roedores, prováveis fonte de infecções para os flebotomíneos ${ }^{5,6}$.

E por ultimo, como não é preconizado tratamento para os animais doentes, cães positivos para LV devem ser eutanasiados ${ }^{7}$ e para LT não se recomenda a eutanásia. Cães errantes devem ser controlados, pois funcionam como fontes de infecção para a leishmaniose visceral.

Medidas educativas, como divulgação à população dos riscos sobre a ocorrência de LT, devem ser inseridas em todos os serviços e ações de controle da enfermidade, requerendo assim, o envolvimento mais efetivo entre a população e órgãos públicos, visando desta forma, a saúde humana e animal ${ }^{5}$.

\section{DISCUSSÃO}

Abordando o tema proposto para a elaboração deste trabalho, deve-se listar pontos chaves que nos levam a comparar as duas enfermidades. Desta forma, foi elaborada uma tabela (Tabela 1 ) no qual se pode analisar a esporotricose e a 
GONTIJO, B.B. et al. Esporotricose e Leishmaniose Tegumentar em cães e gatos: semelhanças e diferenças. PUBVET, Londrina, V. 5, N. 38, Ed. 185, Art. 1250, 2011.

leishmaniose tegumentar sob diversos aspectos. Por serem diagnósticos diferenciais entre si, pela similaridade das lesões $^{6}$, ter conhecimento mais detalhado entre as duas doenças, torna-se importante para o diagnóstico preciso das mesmas.

\section{Tabela 1 - Quadro comparativo entre Esporotricose e Leishmaniose Tegumentar observando diferentes aspectos}

\begin{tabular}{|c|c|c|}
\hline & ESPOROTRICOSE & LEISHMANIOSE TEGUMENTAR \\
\hline Agente Etiológico & $\begin{array}{c}\text { Fungo } \\
\text { Sporothrix schenckii }{ }^{7,25}\end{array}$ & $\begin{array}{c}\text { Protozoários } \\
\text { Leishmania (Leishmania) } \\
\text { amazonensis, } \\
\text { Leishmania (Viannia) guyanensis, L. } \\
\text { (V.) braziliensis }{ }^{7} \\
\end{array}$ \\
\hline $\begin{array}{c}\text { Principal } \\
\text { característica } \\
\text { morfológica do } \\
\text { agente }\end{array}$ & $\begin{array}{c}\text { Fungo dimórfico: } \\
\text { forma filamentosa no ambiente e } \\
\text { leveduriforme no animal }{ }^{19,27}\end{array}$ & $\begin{array}{c}\text { Protozoário pleomorfico: } \\
\text { forma promastigota no vetor, e } \\
\text { após a inoculação no animal, passa } \\
\text { para a forma amastigota } 6 .\end{array}$ \\
\hline $\begin{array}{l}\text { Espécie animal } \\
\text { mais prevalente }\end{array}$ & Gatos $^{20}$ & Cães ${ }^{10,14,21}$ \\
\hline $\begin{array}{c}\text { Distribuição } \\
\text { Mundial }\end{array}$ & $\begin{array}{l}\text { Especialmente observada nas } \\
\text { regiões de climas tropicais e } \\
\text { temperados }{ }^{11} \text {, sendo encontrado } \\
\text { em solos ricos em material } \\
\text { decomposto e em vegetações } \\
\text { deterioradas, atuando como } \\
\text { microorganismo saprófita } \\
11,12,17,18,19,20,25,26\end{array}$ & $\begin{array}{l}\text { Descritas ocorrências em } 88 \text { países, } \\
\text { não determinado por zona climática }\end{array}$ \\
\hline $\begin{array}{l}\text { Formas de } \\
\text { Transmissão }\end{array}$ & $\begin{array}{c}\text { Inoculação direta do agente por } \\
\text { fômites } 15,19,20,26 \text {. }\end{array}$ & $\begin{array}{c}\text { Necessário a presença de um vetor, } \\
\text { o flebotomíne } \\
2,7\end{array}$ \\
\hline Vetor/Reservatório & Não ${ }^{11,12,17,18,19,20,25,26}$ & $\begin{array}{l}\text { Tem como vetor o flebotomíneo do } \\
\text { gênero Lutzomyia. } \\
\text { Acredita-se que animais silvestres } \\
\text { (gambá) e domésticos (cães) } \\
\text { estejam relacionados como } \\
\text { reservatórios da doença, mas sem } \\
\text { comprovação científica } 5,7,21\end{array}$ \\
\hline $\begin{array}{c}\text { Características das } \\
\text { lesões }\end{array}$ & $\begin{array}{c}\text { Micose cutânea granulomatosa a } \\
\text { piogranulomatosa, com formação } \\
\text { de nódulos firmes, placas } \\
\text { ulceradas, não pruriginosas, com } \\
\text { bordas elevadas, crostas e } \\
\text { alopecia } 9,11,26 .\end{array}$ & $\begin{array}{l}\text { Lesões cutâneas ulceradas ou } \\
\text { crostosas } 7,24\end{array}$ \\
\hline
\end{tabular}


GONTIJO, B.B. et al. Esporotricose e Leishmaniose Tegumentar em cães e gatos: semelhanças e diferenças. PUBVET, Londrina, V. 5, N. 38, Ed. 185, Art. 1250, 2011.

\begin{tabular}{|c|c|c|}
\hline \multicolumn{3}{|c|}{ Continuação Tabela 1} \\
\hline $\begin{array}{l}\text { Regiões onde são } \\
\text { observadas as } \\
\text { lesões cães }\end{array}$ & $\begin{array}{l}\text { Tronco, cabeça e pavilhão } \\
\text { auricular }{ }^{17} \text {. }\end{array}$ & $\begin{array}{l}\text { Pavilhão auricular, focinho, bolsa } \\
\text { escrotal e face }{ }^{6,7} \text {. }\end{array}$ \\
\hline $\begin{array}{l}\text { Regiões onde são } \\
\text { observadas as } \\
\text { lesões em gatos }\end{array}$ & $\begin{array}{c}\text { Cabeça, na parte distal dos } \\
\text { membros e/ou base da cauda }{ }^{9,17}\end{array}$ & $\begin{array}{l}\text { Plano nasal, lábios, pavilhão } \\
\text { auricular e pálpebras } 6,7,24\end{array}$ \\
\hline $\begin{array}{l}\text { Evolução do } \\
\text { quadro clínico }\end{array}$ & $\begin{array}{c}\text { Podem ocorrer as formas cutânea, } \\
\text { a linfocutânea e a disseminada no } \\
\text { mesmo animal sendo que a } \\
\text { progressão da infecção ocorre } \\
\text { através de difusão hematogênica } \\
\text { ou tecidual, e a forma disseminada } \\
\text { pode ser fatal }{ }^{26} \text {. }\end{array}$ & $\begin{array}{l}\text { Agravamento das afecções } \\
\text { cutâneas, com surgimento de } \\
\text { lesões mucosas e infecções } \\
\text { secundárias }{ }^{7} \text {. }\end{array}$ \\
\hline Diagnóstico & $\begin{array}{l}\text { Histórico animal associado à } \\
\text { Citopatologia, microscopia direta, } \\
\text { cultura fúngica e necropsia (em } \\
\text { animais que vierem à óbito) } \\
11,16,17,19,20,26\end{array}$ & $\begin{array}{l}\text { Sinais clínicos associados à exame } \\
\text { direto (raspado de pele, biopsia de } \\
\text { pele ou aspirados de medula óssea } \\
\text { e/ou linfonodos), ELISA, RIFI, FC e } \\
\text { PCR } 4,6,7,8,21 .\end{array}$ \\
\hline Diferencial & $\begin{array}{c}\text { Complexo granuloma eosinofífico, } \\
\text { abscesso, leishmaniose, } \\
\text { demodicose, escabiose, } \\
\text { actinomicose, nocardiose, } \\
\text { tuberculose, histoplasmose, } \\
\text { criptococose, corpo estranho e } \\
\text { neoplasias }{ }^{11,12,17,18,19,20,25,26} \text {. }\end{array}$ & $\begin{array}{c}\text { Piodermatites, micoses } \\
\text { (Esporotricose, principalmente), } \\
\text { pênfigo foliáceo, lúpus eritematoso } \\
\text { sistêmico, dermatose responsiva ao } \\
\text { zinco, eritema necrolítico } \\
\text { migratório, adenite sebácea e o } \\
\text { linfoma }{ }^{5,6,7,21,24} \text {. }\end{array}$ \\
\hline Tratamento & $\begin{array}{c}\text { Iodetos inorgânicos, Cetaconazol, } \\
\text { Itraconazol }{ }^{11,17,19,26} \text {. }\end{array}$ & $\begin{array}{l}\text { Não recomendado pelo Ministério } \\
\text { da Saúde }\end{array}$ \\
\hline $\begin{array}{l}\text { Prevenção e } \\
\text { controle }\end{array}$ & $\begin{array}{l}\text { Tratamento de animais doentes, } \\
\text { controle ambiental, educação } \\
\text { sanitária aos proprietários. } \\
\text { Castração de gatos machos }{ }^{3,17,19} \text {. }\end{array}$ & $\begin{array}{l}\text { Controle ambiental e individual, } \\
\text { controle de animais } \\
\text { doentes/eutanasia e controle do } \\
\text { vetor } r^{5,7,10} \text {. }\end{array}$ \\
\hline Zoonose & $\operatorname{Sim} 7,25$ & $\operatorname{Sim}^{5,7,21}$ \\
\hline
\end{tabular}

Analisando a tabela, verifica-se que as duas enfermidades se assemelham quanto as lesões provocadas na pele, sendo caracterizadas por úlceras e formação de crostas tanto nos cães $^{11,26}$ como nos gatos ${ }^{6,7}$. Nos cães, especialmente, se assemelham quanto à localização delas: face e pavilhão auricular ${ }^{6,7,26}$. Curiosamente, os dois agentes etiológicos alteram a sua conformação morfológica no animal infectado, sendo que na esporotricose, o fungo que se encontrava no ambiente na forma filamentosa torna-se leveduriforme ${ }^{19,27}$, enquanto que na LT, o protozoário que no vetor estava na forma flagelada (promastigota) passa para a 
GONTIJO, B.B. et al. Esporotricose e Leishmaniose Tegumentar em cães e gatos: semelhanças e diferenças. PUBVET, Londrina, V. 5, N. 38, Ed. 185, Art. 1250, 2011.

forma não flagelada (amastigota) após repasto do flebotomíneo, infectando macrófagos $^{6,7}$. Outro ponto em comum é a possibilidade do diagnóstico laboratorial através de exame direto, através de raspado de pele por exemplo7,8,19,24, porém, não é a única forma de diagnóstico. Ambas as enfermidades possuem relatos no Brasil e em diversos países do mundo ${ }^{5,6,7,11}$, são zoonoses de grande importância nacional ${ }^{5,6,7,21,24,25}$, e o controle ambiental é forma profilática indispensável, tanto para o desenvolvimento do fungo causador da esporotricose, quanto para o desenvolvimento do flebotomíneo, tão importante no ciclo da $\mathrm{LT}^{3,5,6}$, já que ambos necessitam da matéria orgânica depositadas sobre o solo para o seu desenvolvimento ${ }^{7,19}$.

Mesmo apresentando lesões com características semelhantes, evidenciado no parágrafo anterior, a esporotricose e a LT apresentam algumas diferenças que levam ao direcionamento de suspeita clínica em relação à outra. Como visualizado na Tabela 1, os agentes etiológicos envolvidos são distintos, sendo a esporotricose causada por um fungo ${ }^{7,25}$, S. schenckii, enquanto que a LT é causada por protozoários do gênero Leishmania 5,6,7,21,24, sendo as espécies (Leishmania) amazonensis, (Viannia) guyanensis e L. (V.) braziliensis, as mais comuns no nosso país ${ }^{7}$, e é importante ressaltar que para a transmissão desta enfermidade é necessário a presença de vetor infectado, flebotomíneo do gênero Lutzomyia ${ }^{2,7}$, o que não ocorre na esporotricose, já que para o animal ser infectado é necessário a inoculação direta do agente ${ }^{9,19}$. Em gatos, a incidência da esporotricose é comum ${ }^{20}$ enquanto que a LT é considerada rara ${ }^{7}$, assim, dependendo da espécie animal envolvida, pode-se direcionar a suspeita clínica para uma das duas enfermidades, o que pouparia custos quanto aos exames laboratoriais a serem realizados nos animais. Quanto ao quadro clínico apresentado, animais com esporotricose pode ter progressão da doença, deixando de acometer somente a pele e se difundindo pelos vasos linfáticos, por infecção ascendente ${ }^{26}$, assim como também pode disseminar para os diversos 
GONTIJO, B.B. et al. Esporotricose e Leishmaniose Tegumentar em cães e gatos: semelhanças e diferenças. PUBVET, Londrina, V. 5, N. 38, Ed. 185, Art. 1250, 2011.

órgãos ${ }^{9,19}$ dos animais afetados. Na LT, só ocorre lesão cutânea e mucocutânea (raramente observada) $)^{5,7}$ e casos sistêmicos estão relacionados com a LV, que é causado por outra espécie de Leishmania, a L. infantum ${ }^{7}$.

Como relatado anteriormente, o diagnóstico laboratorial pode ser realizado através de raspado de pele e/ou aspirado das lesões ${ }^{7,8,19,24}$, onde serão visualizados a forma amastigota do protozoário da LT extracelular ou no interior de macrófagos ${ }^{7,14,24}$, e presença de células leveduriformes em exame direto da esporotricose ${ }^{14,19}$. Porém outros exames mais específicos devem ser realizados para a confirmação diagnóstica: quando se suspeita da leishmaniose tegumentar é recomendado o exame sorológico através de RIFI e ELISA ${ }^{4,6,7,8}$. E quando se suspeita de esporotricose o método definitivo é a cultura fúngica ${ }^{17,19}$.

A determinação do diagnóstico definitivo é importante para se determinar a terapêutica a ser realizada no animal afetado, já que sob este aspecto as duas enfermidades se diferenciam bastante, pois animais com esporotricose podem ser tratados com iodetos inorgânicos e antifúngicos sistêmicos ${ }^{11,17,19,26}$, enquanto que para animais com LT não é preconizado o tratamento pelo Ministério da Saúde, que não recomenda a eutanásia dos mesmos como medida de controle ${ }^{7}$. E pensando na prevenção e controle das doenças, elas diferenciam em alguns aspectos: esporotricose - tratamento dos doentes, limpeza do ambiente e instalações com hipoclorito de sódio, cremação de animais que vierem a óbito, castração de machos dos felinos e cuidados com a higienização após qualquer contato com o animal ${ }^{3,17,19}$; na leishmaniose - eutanásia dos animais (mesmo sendo isso ainda tão discutido), limpeza do ambiente e instalações com inseticidas a base de cipermetrina, auxiliado com plantio de citronela e/ou neem no quintal, proteção individual com a utilização de coleiras impregnadas com deltametrina, e controle do vetor ${ }^{5,6,7,10}$. 
GONTIJO, B.B. et al. Esporotricose e Leishmaniose Tegumentar em cães e gatos: semelhanças e diferenças. PUBVET, Londrina, V. 5, N. 38, Ed. 185, Art. 1250, 2011.

\section{CONCLUSÃO}

Como conclusão do trabalho podemos dizer que é de suma importância conhecer sucintamente cada uma das dermatoses aqui descritas, para ser realizado um diagnóstico mais apurado nos animais acometidos, já que as lesões visualizadas macroscopicamente são muito semelhantes e ambas as doenças são zoonoses de preocupação da saúde pública. A espécie animal envolvida já direciona a uma das suspeitas, mas a confirmação laboratorial é necessária para a escolha da medida terapêutica mais adequada ao caso e para informar ao proprietário sobre as medidas de prevenção e controle a serem realizadas na residência onde o animal vive.

Ainda são escassos na literatura, artigos referentes à LT nos animais, o que dificulta no conhecimento adequado do ciclo biológico do parasito e que culmina na eutanásia dos animais afetados, talvez desnecessariamente.

\section{REFERÊNCIAS BIBLIOGRÁFICAS}

1. ALMEIDA JR, H. L. et al. Spontaneus resolution of zoonotic sporotrichosis during pregnancy - case report. Rev. Inst. Med. Trop., S. Paulo, v. 51, n. 4, p. 237-238, jun.-ago., 2009.

2. ALVES, J. R. C. Espécies de Lutzomyia França (Diptera: Psychodidae, Phlebotominae) e Área de Leishmaniose Tegumentar no Município de Carmo, RJ. Neotropical Entomology, v. 36, n. 4, p. 593-596, 2007.

3. BARROS, M. B. L. et al. Esporotricose: a evolução e os desafios de uma epidemia. Rev. Panam. Salud Publica, v. 27, n.6, p.455-460, 2010.

4. BARROSO-FREITAS, A. P. T. et al. Accuracy of an ELISA and indirect immunofluorescence for the laboratory diagnosis of American tegumentary leishmaniasis. Transactions of the Royal Society of Tropical Medicine and Hygiene, n. 103, p. 383-389, 2009.

5. BRASIL. Ministério da Saúde. Secretaria de Vigilância em Saúde. Departamento de Vigilância Epidemiológica. Doenças infecciosas e parasitárias: guia de bolso / Ministério da Saúde, Secretaria de Vigilância em Saúde, Departamento de Vigilância Epidemiológica. - 7. ed. rev. Brasília: Ministério da Saúde, 2008. 372 p.

6. Brasil. Ministério da Saúde. Secretaria de Vigilância em Saúde. Manual de Vigilância da Leishmaniose Tegumentar Americana / Ministério da Saúde, Secretaria de Vigilância em Saúde. - 2. ed. atual. - Brasília : Editora do Ministério da Saúde, 2007. 180 p. 
7. BRUM, L. C. et al. Principais dermatoses zoonóticas de cães e gatos. Rev. Clínica Veterinária, a. XII, n. 69, p. 29-46, jul./ago., 2007.

8. CATALDO, J. I. et al. Immunoenzymatic assay for the diagnosis of American Tegumentary Leishmaniasis using soluble and membrane-enriched fractions from infectious Leishmania (Viannia) braziliensis. Journal of Clinical Laboratory Analysis, $\mathrm{n}$. 24, p. 289-294, 2010.

9. CORGOZINHO, K. B. et al. Um caso atípico de esporotricose felina. Acta Scientiae Veterinariae, v. 34, n.2, p. 167-170, 2006.

10. DANTAS-TORRES, F. Canine leishmaniosis in South America. Parasites \& Vectors, 2009, 2(Suppl 1), 8p.

11. FILGUEIRA, K. D. Esporotricose na espécie canina: relato de um caso na cidade de Mossoró, RN. Ciência Animal Brasileira, v. 10, n. 2, p. 673-677, abr./jun. 2009.

12. MARQUES, S. A. et al. Esporotricose do gato doméstico (Felis catus): Transmissão Humana. Rev. Inst. Med. Trop., São Paulo, v. 35, n. 4, p. 327-330, jul.-ago., 1993.

13. MEINERZ, R. M. et al. Suscetibilidade in vitro de isolados de Sporothrix schenckii frente à terbinafina e itraconazol. Rev. Soc. Bras. Med. Trop., v. 40, n.1, p. 60-62, jan.fev., 2007.

14. MIRANDA, L. H. M. et al. Comparative histopathological study of Sporotrichosis and American Tegumentary Leishmaniosis in dogs from Rio de Janeiro. J. Comp. Path., v.143, p. 1-7, 2010.

15. MIRANDA, L. H. M. et al. Histopathology of canine sporotrichosis: a morphological study of 86 cases from Rio de Janeiro (2001-2007). Mycopathologia, n. 168, p. 79-87, 2009.

16. MIRANDA, L. H. M., et al. Evaluation of immunohistochemistry for the diagnosis of sporotrichosis in dogs. The Veterinary Journal, 2011.

17. MONTEIRO, H. R. B.; TANENO. J. C.; NEVES, M. F. Esporotricose em felinos domésticos. Rev. Cient. Elet. Med. Vet., a. VI, n. 10, 6p., jan., 2008.

18. NOBRE, M. O. et al. Differences in virulence between isolates of feline Sporotrichosis. Mycopathologia, n. 160, p. 43-49, 2005.

19. PAULA, R. B. Esporotricose Canina e Felina - Revisão de Literatura. 2008, $48 f$. Monografia (Pós-Graduação) - Universidade Castelo Branco, Rio de Janeiro.

20. PEREIRA, S. A. et al. Sensitivity of cytopathological examination in the diagnosis of feline sporotrichosis. Journal of Feline Medicine and Surgery, n. 13, p. 220-223, 2011.

21.REITHINGER, R.; DAVIES, C. R. American cutaneous leishmaniasis in domestic dogs: an example of the use of the polymerase chain reaction for mass screening in epidemiological studies. Transactions of the Royal Society of Tropical Medicine and Hygiene, n. 96, Suppl. I, 2002, 4p.

22. SANTIAGO, M. A. et al. Differentiation between canine cutaneous and visceral leishmaniasis by the detection of immunoglobulin G specific for Leishmania (Viannia) braziliensis and Leishmania (Leishmania) chagasi antigens using flow cytometry. Veterinary Parasitology, v.154, p. 341-346, 2008. 
23. SCHUBACHI, T. M. P. et al. Utilidade do coágulo sangüíneo para o isolamento de Sporothrix schenckii de gatos naturalmente infectados. Braz. J. Vet. Res. Anim. Sci., v. 41, n. 6, p. 404-408, 2004.

24. SOUZA, A. L. et al. Domestic feline cutaneous leishmaniasis in the municipality of Ribas do Rio Pardo, Mato Grosso do Sul estate, brazil: a case report. J. Venom. Anim. Toxins. Incl. Trop. Dis., v. 15, n. 2, p. 359-365, 2009.

25. SOUZA, L. L. et al. Isolation of Sporothrix schenkii from the nails of healthy cats. Brazilian Journal of Microbiology. n. 37, p. 372-374, 2006.

26. SOUZA, N. T. et al. Esporotricose canina: relato de caso. Arq. Bras. Med. Vet. Zootec., v. 61, n. 3, p. 572-576, 2009.

27. XAVIER, M. O. et al. Esporotricose felina com envolvimento humano na cidade de Pelotas, RS, Brasil. Ciência Rural, Santa Maria, v. 34, n. 6, p. 1961-1963, nov-dez, 2004. 